\title{
AVALIAÇÃO DA ATIVIDADE ANTIMICROBIANA E DETERMINAÇÃO DA CONCENTRAÇÃO MÍNIMA INIBITÓRIA (CMI) DA OLEORRESINA DE COPAÍBA
}

\author{
EVALUATION OF ANTIMICROBIAL ACTIVITY AND DETERMINATION OF \\ MINIMUM INHIBITORY CONCENTRATION (MIC) OF COPAIBA OLEORESIN
}

Josiane Elizabeth Almeida-Silva ${ }^{1 *}$, Taiara de Andrade Picanço ${ }^{2}$, Iasmin Lais Damasceno Paranatinga ${ }^{2}$, José Jeosafá Vieira de Sousa Júnior ${ }^{2}$, Silvia Katrine da Silva Escher ${ }^{2}$, Elaine Cristina Pacheco de Oliveira ${ }^{2}$

1 Universidade Federal do Oeste do Pará, Programa de Pós-graduação em Biociências.

${ }^{2}$ Universidade Federal do Oeste do Pará, Instituto de Biodiversidade e Florestas.

* Rua Vera Paz, S/N - Salé, Santarém/PA, Brasil. CEP 68040-470. E-mail: josialmeida08@gmail.com

Submetido em: 16/11/2019; Aceito em: 02/06/2020.

\section{RESUMO}

A copaíba pertence ao gênero Copaifera que produz um exsudado extraído do tronco da árvore, utilizado na medicina popular para fins terapêuticos. Com o objetivo de avaliar a composição química e a atividade antimicrobiana in vitro da oleorresina de Copaifera reticulata Ducke, coletadas em diferentes períodos sazonais, na Floresta Nacional do Tapajós, frente às bactérias Staphylococcus aureus, Staphylococcus epidermidis, Pseudomona aeruginosa, e à levedura Candida krusei, foi realizado ensaios de atividade antimicrobiana por disco difusão e microdiluição em placas, e avaliada a composição química da oleorresina por Cromatografia Gasosa-Espectroscopia de Massa (CG-EM). A atividade antimicrobiana constatou halos de inibição indicando que houve ação da óleorresina frente às bactérias $S$. aureus $(15,5$ e 16,7 mm) e $S$. epidermidis $(17,5$ e $17,3 \mathrm{~mm})$, dos períodos chuvoso e seco, respectivamente. A determinação da Concentração Mínima Inibitória (CMI) demonstrou que a oleorresina coletada no período seco apresentou uma CMl de $1,63 \mathrm{mg} / \mathrm{ml}$ para ambas as cepas. As amostras apresentaram atividade bactericida e bacteriostática para $S$. aureus e $S$. epidermidis, respectivamente. A análise química obteve como componente majoritário $\beta$ - cariofileno, sendo $39.91 \%$ para período chuvoso e $41.67 \%$ para período seco. Embora haja diferença nos resultados quando comparados os períodos sazonais, a oleorresina possui uma comprovada ação antimicrobiana e um potencial como matéria-prima para produtos com essa finalidade.

Palavras-chave: Composição química. Concentração mínima inibitória. Copaifera. FLONA do Tapajós. Oleorresina. 


\begin{abstract}
Copaiba belongs to the Copaifera genus, which produces an exudate extracted from the tree trunk, used in popular medicine for therapeutic purposes, with the objective of evaluating chemical composition and the antimicrobial activity in vitro of the oleoresin from the Copaifera reticulata Ducke, collected in different seasonal periods, in the Tapajós National Forest, against Staphylococcus bacteria aureus, Staphylococcus epidermidis, Pseudomona aeruginosa, and the yeast Candida krusei, antimicrobial activity tests were performed by disk diffusion and microdilution in plates, and evaluated the chemical composition of the oleoresin by Gas Chromatography-Mass Spectroscopy (GC-MS). The antimicrobial activity found halos of inhibition indicating that there was action of oleoresin against bacteria $\mathrm{S}$. aureus (15.5 and $16.7 \mathrm{~mm}$ ) and $\mathrm{S}$. epidermidis (17.5 and $17.3 \mathrm{~mm}$ ), from the rainy and dry periods, respectively. The determination of the Minimum Inhibitory Concentration (MIC) demonstrated that the oleoresin collected in the dry period showed an MIC of $1.63 \mathrm{mg} / \mathrm{ml}$ for both strains. The samples showed bactericidal activity and bacteriostatic for $\mathrm{S}$. aureus and S. epidermidis, respectively. The chemical analysis obtained as a major component $\beta$-karyophylene, with $39.91 \%$ for rainy season and $41.67 \%$ for dry season. Although there is a difference in results when comparing seasonal periods, the oleoresin has proven antimicrobial action and potential as a raw material for products with that purpose.
\end{abstract}

Keywords: Chemical composition. Copaifera. Minimum Inhibitory Concentration. Oleoresin. Tapajós' FLONA.

\title{
INTRODUÇÃO
}

O gênero Copaifera pertence à família Fabaceae, e possui aproximadamente 72 espécies descritas, sendo que 16 dessas são encontradas exclusivamente no Brasil. Popularmente conhecida como copaíbeira ou pau d'óleo, é uma árvore nativa de regiões tropicais e no Brasil é adaptada à diversos climas, onde se desenvolve principalmente no Norte e Nordeste (HECK et al., 2012). Esta planta pode viver em média 400 anos, atingir uma altura entre 25 a 40 metros, e diâmetro entre 0,4 e 4 metros (MARTINELLI; MORAES, 2014). Possui a casca aromática, folhagem densa, flores pequenas e frutos secos, do tipo vagem (PIERI, 2009).

A oleorresina é obtida da árvore através de um furo realizado no tronco, e se apresenta como óleo transparente, de coloração variando entre amarelo claro ao castanho dourado, de viscosidade variável, odor forte e sabor amargo (LOURENÇO, 2009), composta por uma parte resinosa constituída por diterpenos (cerca de 55 a 60\%), e uma fração volátil formada principalmente por sesquiterpenos (VEIGA JUNIOR; PINTO, 2002). Contudo, estudos apontam que a composição química da oleorresina pode alterar em função das condições edafoclimáticas, dentre elas, a sazonalidade (COSTA, 2017).

No Brasil, a oleorresina de copaíba é amplamente utilizada na medicina popular, sendo administrada por via oral e/ou por aplicação tópica da oleorresina in natura ou em formulações (LEANDRO et al., 2012). Sendo 
utilizada no tratamento de infecções das vias urinárias, atuando como antiinflamatória, antisséptica, também no tratamento de cistite, incontinência urinária e sífilis; para úlceras e feridas no útero; para as infecções da derme e mucosa, em dermatites, eczemas, psoríases e ferimentos; para as vias respiratórias, é usada como antiasmática, expectorante, no tratamento de bronquite, faringite, hemoptise, pneumonia e sinusite; pode ser aplicada como analgésico, antidiarréico, cicatrizante, afrodisíaco, antioxidante, antitetânico, anti-herpético, bactericida, anticancerígeno, antitumoral, no tratamento de leishmaniose, reumatismo, hemorragias, paralisia, dores de cabeça e picadas de cobra (PEDREIRA, 2007; PIERI et al., 2009; CARVALHO; MIKLE, 2014), em que essas atividades estão associadas a ação dos compostos químicos encontrados nesta oleorresina.

Dentre as espécies de Copaifera descritas, a Copaifera reticulata Ducke é apontada por Martins-da-Silva et al. (2008) como uma das espécies predominantes na Amazônia brasileira, amplamente distribuída no Pará, também é encontra a sudoeste do Amapá, sudeste de Roraima e norte do Mato Grosso.

Nesse contexto, este trabalho tem por objetivo analisar a composição química e a atividade antimicrobiana in vitro, em função das alterações sazonais da oleorresina de Copaifera reticulata Ducke.

\section{MATERIAL E MÉTODOS}

\section{Área de estudo}

A coleta da oleorresina de Copaifera reticulata Ducke foi realizada em abril (período chuvoso) e setembro (período seco) de 2016, na Floresta Nacional do Tapajós (FLONA do Tapajós), localizada no município de BelterraPA, no km 117 da rodovia BR-163, (S 03 21' 09,9" e W 55'01' 26,5'), sob a autorização do SISBIO: 56937, de 06 de dezembro de 2015.

\section{Identificação botânica}

A identificação botânica foi realizada pela Embrapa Amazônia Oriental, onde a exsicata foi depositada no herbário Instituto Agronômico do Norte (IAN), sob o registro NID: 58/2016.

\section{Coleta da oleorresina de copaíba e separação das frações}

A árvore foi perfurada em duas posições em direção ao centro do tronco, aproximadamente $1 \mathrm{~m}$ a $1,50 \mathrm{~m}$ em relação ao solo, com auxílio de um trado tradicional de $2 \mathrm{~cm}$ de diâmetro e $45 \mathrm{~cm}$ de comprimento. Foi utilizado um cano de PVC medindo $3 / 4$ de diâmetro e $10 \mathrm{~cm}$ de comprimento, em cada um dos furos feitos no tronco da árvore para evitar possíveis resíduos de madeira e auxiliar nas coletas posteriores. Após a coleta os canos foram vedados com uma tampa de PVC visando proteger a árvore contra infestações causadas por fitopatógenos e insetos. A oleorresina foi coletada com auxílio de calha metálica e armazenada em frascos de vidro âmbar e identificados (OLIVEIRA, 2006).

A separação das frações resinosa e volátil foi feita através do método de hidrodestilação simples, em um período de $6 \mathrm{~h}$ de processo. 


\section{Análise por cromatografia gasosa acoplada à espectrometria de massa (CG-EM)}

A análise das amostras da fração volátil da oleorresina foi realizada em Cromatógrafo Gasoso Acoplado a Espectrômetro de Massas (CG/EM), em um sistema Agilent Technologies AutoSystem XL GC-MS operando no modo El a $70 \mathrm{eV}$, equipado com um injetor split/ splitless $\left(250^{\circ} \mathrm{C}\right)$. A temperatura da linha de transferência era de $280^{\circ} \mathrm{C}$. Utilizou-se o gás hélio como transportador $(1,5$ $\mathrm{mL} / \mathrm{min})$ e as colunas capilares utilizadas foram HP $5 \mathrm{MS}(30 \mathrm{~m} \times 0,25 \mathrm{~mm}$, espessura de película 0,25 mm) e HP Innowax (30m x 0,32 mm i.d., espessura de película $0,50 \mathrm{~mm}$ ). $O$ volume injetado foi de $1 \mu \mathrm{L}$ da oleorresina.

A identificação dos constituintes da fração volátil da oleorresina de Copaifera reticulata Ducke foi realizada com base no índice de retenção (IR), determinado com referência das séries homólogas de $n$-alcanos, $C_{7}-C_{30}$, em condições experimentais idênticas, por comparação dos Espectros de Massa (EM) com a literatura (ADAMS, 1995) e pela correspondência dos espectros de massas com a biblioteca NIST/EPA/NHI. As quantidades relativas dos componentes individuais foram calculadas com base na área do pico CG.

\section{Avaliação da atividade antimicrobiana da oleorresina de Copaifera reticulata Ducke}

A atividade antimicrobiana da oleorresina de C. reticulata Ducke foi determinada pelo método disco de difusão (BAUER et al., 1966), em placas de petri contendo Àgar Mueller Hinton (MH) para bactérias, e Ágar Sabouraud Dextose para leveduras. Foram dispostos equidistantes discos de papel filtro de $0,5 \mathrm{~cm}$ de diâmetro embebidos com $10 \mu \mathrm{L}$ da oleorresina de copaíba, nos meios previamente inoculados com $100 \mu \mathrm{L}$ da suspensão microbiana padronizada na escala 0,5 Mcfarland correspondendo a $10^{8} \mathrm{UFC} / \mathrm{mL}$ (bactérias) e $10^{4}$ esporos $/ \mathrm{mL}$ (fungos).

Os microrganismos testes utilizados foram: bactérias Gram-positivas Staphylococcus epidermides (ATCC 12228) e Staphylococcus aureus (ATCC 23235); bactérias Gram-negativas Pseudomonas aeruginosa (ATCC 19429) e Escherichia coli (ATCC 25922) e a levedura Candida krusei (ATCC 40147). O teste foi realizado em triplicata e as placas foram mantidas a $37 \stackrel{\circ}{\circ} \mathrm{C}$ por $24 \mathrm{~h}$ (bactérias) e 48h (leveduras). Como controle positivo utilizou-se o antibiótico cefuroxina $30 \mu \mathrm{g}$ (bactérias) e nistatina a $100 \mu \mathrm{g}$ (levedura).

A Concentração Mínima Inibitória (CMI) foi determinada apenas para discos contendo os microrganismos sensíveis, através do método de microdiluição em placa de 96 poços, conforme CLSI (2010). Previamente, foi preparado uma solução a $1.000 \mathrm{mg}$ a partir da oleorresina, solubilizada no meio de cultura caldo Muller Hinton (MH). Nos poços da linha $A$ à $G$ foram dispensados $100 \mu \mathrm{L}$ do respectivo meio de cultura líquido $\mathrm{MH}$ e em seguida foi dispensada uma alíquota de $100 \mu \mathrm{L}$ das soluções mães no poço da linha A1 até $A 12$, iniciando a microdiluição em série até os poços da linha $G$ das colunas de 1-12. Utilizando as concentrações decrescentes 104,7; 52,35; 26,17; 13,09; 6,$54 ; 3,27 ; 1,63 \mathrm{mg} / \mathrm{mL}$. A linha $\mathrm{H}$ foi destinada aos controles em duplicata, controle de esterilidade (CE), Controle de viabilidade no inóculo (C-) e Controle do antibiótico $\left(\mathrm{C}_{+}\right)$. Após o período de incubação as placas foram mantidas a 
$37 \stackrel{\circ}{\mathrm{C}}$ por $24 \mathrm{~h}$, sendo posteriormente reveladas com $50 \mu \mathrm{L}$ da solução de Resazurina a $0,01 \%$.

A mudança de coloração dos poços inicialmente azul, contendo as diferentes concentrações da oleorresina, para vermelho, indicará a negatividade do teste, e a permanência da cor azul indicará a positividade. Nos poços de controle, a permanência da cor azul indicará ação antimicrobiana e a mudança de coloração para vermelho indicará a viabilidade do inóculo. A Concentração Mínima Bactericida (CMB) foi determinada pela subcultura dos poços correspondendo a CMI revelada com a Resazurina, realizadas em meio de cultura Àgar Muller Hinton, a $37 \stackrel{\circ}{\circ}$ por 24h.

\section{Análise estatística}

Os resultados foram expressos como média aritmética \pm variância. Para comparação das médias foi utilizado Análise de Variância One-Way (ANOVA), com posterior realização do teste de Tukey para múltiplas comparações. $O$ nível de significância adotado foi de $p<0,05$.

\section{RESULTADOS E DISCUSSÃO}

Composição química da fração volátil da oleorresina de C. reticulata Ducke

$\mathrm{Na}$ Tabela 1 são apresentados os vinte e cinco componentes químicos identificados com base nos seus espectros de massas, comparados com os da literatura e com a biblioteca eletrônica, e em seus índices de retenção, obtidos por comparação de tempos de retenção.

De acordo com os dados obtidos, os compostos majoritários encontrados foram $\beta$-cariofileno $(39,91 \%$ no período chuvoso e $41,67 \%$ no período seco), $\beta$-bisaboleno ( $7,38 \%$ no período chuvoso e $18,62 \%$ no período seco), $\alpha$ - humuleno ( $3,15 \%$ no período chuvoso e $5,38 \%$ no período seco), $\alpha$ Bergamoteno ( $11,32 \%$ no período chuvoso e $5,24 \%$ no período seco) e $\beta$ selineno ( $1,72 \%$ no período chuvoso e $3,27 \%$ no período seco).

A variabilidade tanto na composição química, quanto na produção da oleorresina estão relacionadas a fatores como genética, nutrição, luminosidade, sazonalidade, fertilidade do solo, dendrometria, mas principalmente a fatores bióticos, pois sua produção é resultado da desintoxicação do organismo vegetal, servindo como defesa contra a ação de fungos, insetos, bactérias e outros agentes lesivos (BARBOSA, 2012; GARCIA; YAMAGUCHI, 2012; LUCCA, 2013; COSTA, 2017).

No trabalho realizado por Ziech et al. (2013), foi identificado o $\beta$ cariofileno, $\alpha$-bergamoteno, $\beta$-selineno, $\alpha$-humuleno, $\alpha$-selineno e $\beta$-bisaboleno como os componentes majoritários na oleorresina de $C$. reticulata Ducke coletado em maio de 2011 na FLONA do Tapajós, período chuvoso. Zoghbi et al. (2009), em estudo acerca da variabilidade da composição química de C. reticulata Ducke em diferentes municípios, coletadas no período seco, observaram que a oleorresina coletada em Almeirim/ Pará possui como componentes majoritários o $\beta$-cariofileno (13\%), $\alpha$-bergamoteno $(29,2 \%)$ e $\beta$ bisaboleno $(28,5 \%)$, quanto a oleorresina coletada em Belterra/ Pará, apresentou como constituintes majoritários o $\beta$-cariofileno $(11,3 \%), \alpha$ bergamoteno $(25,9 \%)$ e $\beta$-bisaboleno $(36,9 \%)$, e a oleorresina coletada em 
Curionópolis/ Pará apresentou o $\beta$-cariofileno (19\%), $\alpha$-bergamoteno $(8,1 \%), \alpha$ selineno (8,2\%), $\alpha$-selineno (5,4\%), $\beta$-bisaboleno $(18,2 \%)$ e óxido de cariofileno $(15,2 \%)$, demonstrando que a composição da oleorresina de C. reticulata Ducke varia entre os indivíduos da mesma espécie, dependendo de seu potencial genético e fatores ambientais aos quais os indivíduos estão sujeitos.

Tabela 1 - Composição química da fração volátil da oleorresina de C. reticulata Ducke da FLONA do Tapajós no período chuvoso e seco.

\begin{tabular}{|c|c|c|c|c|c|}
\hline Compostos & $\mathbf{I R}^{\mathbf{C}}$ & $\mathbf{I R}^{\mathbf{S}}$ & $\begin{array}{l}\begin{array}{c}\text { Período } \\
\text { Chuvoso }\end{array} \\
\text { Teor (\%) } \\
\end{array}$ & $\begin{array}{c}\text { Período } \\
\text { Seco }\end{array}$ & $\begin{array}{l}\text { Fórmula } \\
\text { Molecular }\end{array}$ \\
\hline$\alpha$-Elemeno & 1339 & 1344 & 0.17 & 0.46 & $\mathrm{C}_{15} \mathrm{H}_{24}$ \\
\hline a-Cubebeno & 1353 & 1351 & 1.04 & 0.73 & $\mathrm{C}_{15} \mathrm{H}_{24}$ \\
\hline a-Copaeno & 1376 & 1376 & 2.63 & 4.05 & $\mathrm{C}_{15} \mathrm{H}_{24}$ \\
\hline$\beta$-Cariofileno & 1405 & 1404 & 39.91 & 41.67 & $\mathrm{C}_{15} \mathrm{H}_{24}$ \\
\hline$\alpha$-Cedreno & 1411 & 1409 & 0.45 & 1.39 & $\mathrm{C}_{15} \mathrm{H}_{24}$ \\
\hline$\alpha$-Bergamoteno & 1436 & 1436 & 11.32 & 5.24 & $\mathrm{C}_{15} \mathrm{H}_{24}$ \\
\hline a-Aromadendreno & 1445 & 1439 & - & 0.26 & $\mathrm{C}_{15} \mathrm{H}_{24}$ \\
\hline $\begin{array}{c}\text { a-Humuleno } \\
\text { Germacreno-D }\end{array}$ & $\begin{array}{l}1455 \\
1480\end{array}$ & $\begin{array}{l}1454 \\
1480\end{array}$ & $\begin{array}{l}3.15 \\
5.84\end{array}$ & $\begin{array}{l}5.38 \\
8.15\end{array}$ & $\begin{array}{l}\mathrm{C}_{15} \mathrm{H}_{24} \\
\mathrm{C}_{15} \mathrm{H}_{24}\end{array}$ \\
\hline a-Curcumeno & 1484 & 1483 & 0.93 & 0.91 & $\mathrm{C}_{15} \mathrm{H}_{24}$ \\
\hline$\beta$-Selineno & 1485 & 1485 & 1.72 & 3.27 & $\mathrm{C}_{15} \mathrm{H}_{24}$ \\
\hline $\begin{array}{l}\text { Bicyclogermacreno } \\
\boldsymbol{\beta} \text {-Bisaboleno }\end{array}$ & $\begin{array}{l}1501 \\
1510\end{array}$ & $\begin{array}{l}1502 \\
1509\end{array}$ & $\begin{array}{l}0.22 \\
7.38\end{array}$ & $\begin{array}{c}1.05 \\
18.62\end{array}$ & $\mathrm{C}_{15}^{-} \mathrm{H}_{24}$ \\
\hline $\begin{array}{c}\beta- \\
\text { Sesquifelandreno }\end{array}$ & 1524 & 1524 & 0.31 & 0.51 & $\mathrm{C}_{15} \mathrm{H}_{24}$ \\
\hline ס-Cadineno & 1510 & 1513 & 2.54 & 0.87 & $\mathrm{C}_{15} \mathrm{H}_{24}$ \\
\hline a-Cadideno & 1538 & 1538 & 3.19 & 0.83 & $\mathrm{C}_{15} \mathrm{H}_{24}$ \\
\hline $\begin{array}{l}\text { Germacreno-B } \\
\text { Spathulenol }\end{array}$ & $\begin{array}{l}1561 \\
1577\end{array}$ & $\begin{array}{l}1556 \\
1576\end{array}$ & $\begin{array}{l}4.28 \\
0.45\end{array}$ & $\begin{array}{c}1.57 \\
-\end{array}$ & $\begin{array}{l}\mathrm{C}_{15} \mathrm{H}_{24} \\
\mathrm{C}_{15} \mathrm{H}_{24} \mathrm{O}\end{array}$ \\
\hline Cariofileno óxido & 1580 & 1581 & 1.87 & 2.45 & $\mathrm{C}_{15} \mathrm{H}_{24} \mathrm{O}$ \\
\hline $\begin{array}{c}\text { Cedrol } \\
\text { Eudesmol }\end{array}$ & $\begin{array}{l}1593 \\
1637\end{array}$ & $\begin{array}{l}1596 \\
1635\end{array}$ & 2.43 & $\begin{array}{l}1.07 \\
0.19\end{array}$ & $\begin{array}{l}\mathrm{C}_{15} \mathrm{H}_{26} \mathrm{O} \\
\mathrm{C}_{15} \mathrm{H}_{26} \mathrm{O}\end{array}$ \\
\hline a-Muurolol & 1641 & 1644 & 0.52 & 0.12 & $\mathrm{C}_{15} \mathrm{H}_{26} \mathrm{O}$ \\
\hline a-Cadinol & 1665 & 1653 & 1.61 & 0.93 & $\mathrm{C}_{15} \mathrm{H}_{26} \mathrm{O}$ \\
\hline Cadaleno & 1672 & 1674 & - & 0.26 & $\mathrm{C}_{15} \mathrm{H}_{28}$ \\
\hline$\beta$-Vertivono & 1811 & 1809 & 0.39 & - & $\mathrm{C}_{15} \mathrm{H}_{22} \mathrm{O}$ \\
\hline
\end{tabular}

Total identificado (\%)

$92.35 \quad 99.98$

Notas: * $\mathrm{R}^{\mathrm{C}}$ - Índice de Retenção do período Chuvoso; $\mathrm{IR}^{\mathrm{S}}$ - Índice de Retenção do período Seco.

Fonte: os autores

Os estudos citados, corroboram a presença dos constituintes majoritários e a variabilidade quanto aos respectivos teores identificados neste trabalho, em que, em ambos períodos sazonais, os compostos majoritários 
foram $\beta$-cariofileno (39,91\%; 41,67\%), $\alpha$-bergamoteno $(11,32 \% ; 5,24 \%), \alpha$ humuleno (3,15\%; 5,38\%), germacreno-D (5,84\%; 8,15\%), $\beta$-selineno $(1,72 \%$; $3,27 \%)$, $\beta$-bisaboleno (7,38\%; 18,62\%).

Atividade antimicrobiana da oleorresina de $C$. reticulata Ducke.

A oleorresina de Copaifera reticulata Ducke coletada nos períodos chuvoso e seco foi ativa apenas contra as bactérias Staphylococcus aureus e Staphylococcus epidermidis (Figura 1).

Figura 1 - Ensaio de disco difusão em $\mathrm{MH}$, da amostra da oleorresina de $C$. reticulata Ducke, coletadas no período seco, frente a $S$. aureus (1) e $S$. epidermidis (2). As representações: $R_{1}, R_{2}$ e $R_{3}$ correspondem as repetições do ensaio com a oleorresina, C- controle negativo, $\mathrm{C}+$ controle positivo.
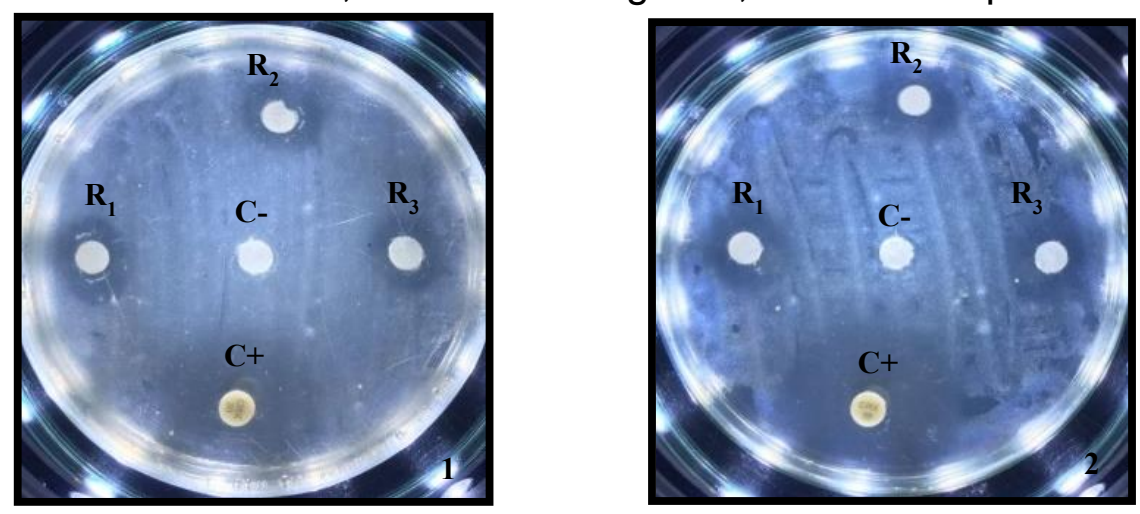

Fonte: os autores

A oleorresina de $C$. reticulata Ducke do período seco foi mais ativa, com halo de inibição de $16,7 \mathrm{~mm}$ para $S$. aureus e $17,5 \mathrm{~mm}$ para $S$. epidermidis, em relação à oleorresina do período chuvoso, o halo de inibição foi de $15,5 \mathrm{~mm}$ para S. aureus e 17,3 mm para S. epidermidis (Figura 2). Huang et al. (2012), descrevem o potencial do $\beta$-cariofileno na inibição do crescimento bacteriano. Pichette et al. (2006) relatam que embora não existam registros sobre a atividade do $\alpha$-bergamoteno na sua forma isolada, a literatura apresenta evidências de que este composto também contribui para a atividade antibacteriana detectada. Existem também outros compostos da oleorresina de copaíba presentes em menor quantidade, que podem desempenhar função na atividade antibacteriana como é o caso do $\alpha$-humuleno (PICHETTE et al., 2006).

Segundo Lucca (2013), os compostos $\beta$-Cariofileno e o $\beta$-Bisaboleno apresentam importância por suas propriedades farmacológicas, antibacteriana, antifúngica, anti-inflamatória, antiedêmica e analgésica. Outros constituintes como $\alpha$-humuleno e $\beta$-selineno apresentam aromas marcantes, sendo utilizados principalmente pela indústria de perfumes (LIMA et al., 2020).

A Concentração Mínima Inibitória (CMI) e a Concentração Mínima Bactericida $(\mathrm{CMB})$ da oleorresina no período seco para $S$. aureus e $S$. epidermidis foi de $1,63 \mathrm{mg} / \mathrm{mL}$, e para as amostras do período chuvoso foi de $6,54 \mathrm{mg} / \mathrm{mL}$ para $S$. aureus e de $1,63 \mathrm{mg} / \mathrm{mL}$ para $S$. epidermidis (Figura 3 ). Considerando os critérios sugeridos por Holetz et al. (2002), a atividade 
antimicrobiana é considerada boa quando a amostra apresenta CMI $\leq 100$ $\mu \mathrm{g} / \mathrm{mL}$, moderada $100<\mathrm{CMI} \leq 500 \mu \mathrm{g} / \mathrm{mL}$, fraca $500<\mathrm{CMI} \leq 1000 \mu \mathrm{g} / \mathrm{mL}$ e inativa $\mathrm{CMI}>1000 \mu \mathrm{g} / \mathrm{mL}$. A amostra do período seco apresentou moderada atividade antibacteriana, enquanto a amostra coletada em período chuvoso apresentou fraca atividade frentes às cepas avaliadas.

Figura 2 - Análise das médias da atividade antimicrobiana da oleorresina de $C$. reticulata Ducke dos períodos seco e chuvoso, frente às bactérias $S$. aureus e S. epidermidis.

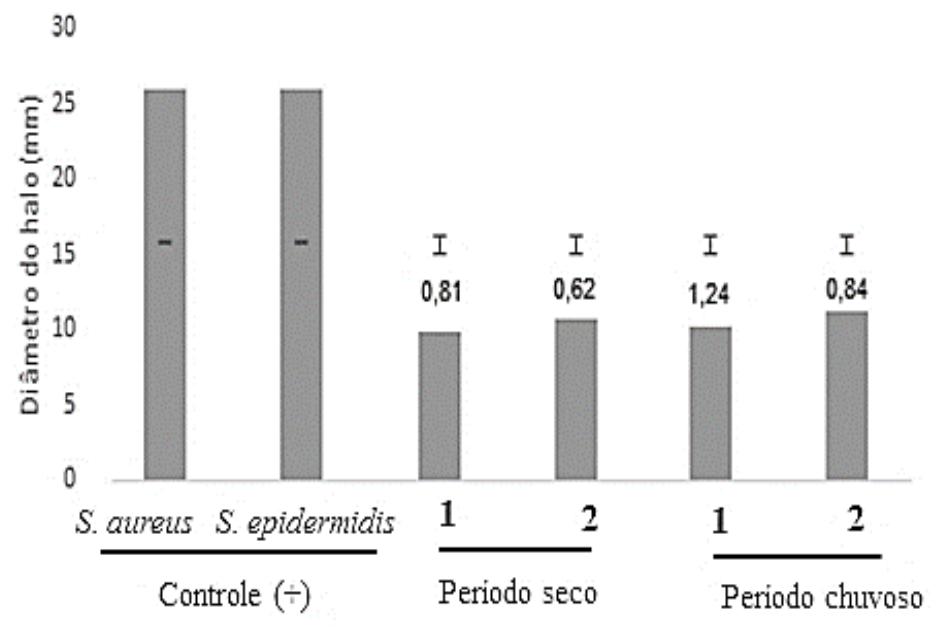

Fonte: os autores

Figura 3 - CMl por microdiluição em placas da oleorresina de $C$. reticulata Ducke frente as cepas $S$. aureus e $S$. epidermidis. ORc (oleorresina do período chuvoso) ORs (oleorresina do período seco).

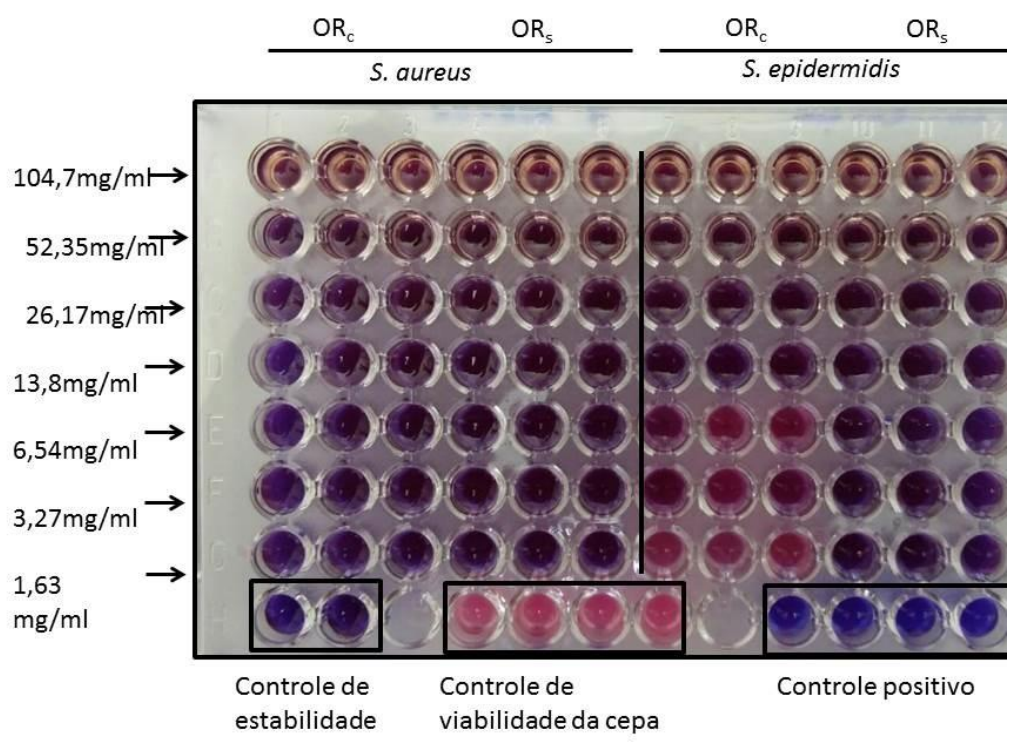

Fonte: os autores 
O estudo realizado por Ziech et al. (2013) sobre a atividade antimicrobiana da oleorresina de copaíba frente a Staphylococcus coagulase positiva multirresistentes, evidenciou através da CMI e CMB, a ação antimicrobiana, comprovando a eficácia da oleorresina em concentrações inferiores a 2,62 $\mathrm{mg} / \mathrm{mL}$.

Outro estudo que corrobora com os resultados encontrados neste trabalho é o apresentado por Santos et al. (2008) que confirma a atividade bactericida da óleorresina de $C$. reticulata Ducke frente a cepas de $S$. aureus, $S$. epidermidis e $S$. aureus meticilina resistente (MRSA), no qual foi verificado a resistência de Gram-negativas Klebsiella pneumoniae (ATCC 13883) (ATCC 25933), E. coli (ATCC 25922), Shigella flexneri (ATCC 12022) e Pseudomonas aeruginosa (ATCC 27853), utilizando a técnica de microdiluição em caldo, e apontam uma CMl de 62,5 $\mathrm{\mu g} / \mathrm{mL}$. No estudo de Pacheco et al. (2006) utilizando essas mesmas condições, foram testadas onze amostras de oleorresina de copaíba, sendo cinco Copaifera multijuga Hayne e seis Copaifera sp., e não observaram inibição de $E$. coli e $P$. aeruginosa.

Nascimento et al. (2007) observaram em seu trabalho a atividade antimicrobiana do $\beta$-bisaboleno frente a cepas de Staphylococcus aureus e que a sinergia com o $\beta$-lactâmicos pode ser eficaz frente a cepas $\beta$-lactamase positivas. No entanto, é importante ressaltar que os distintos resultados entre os trabalhos podem estar relacionados às diferenças nas concentrações dos metabólitos na composição química das oleorresinas dentro da própria espécie.

\section{CONCLUSÃO}

A partir dos dados obtidos, pode-se observar que foram encontradas variações no conteúdo dos componentes majoritários das oleorresinas obtidos em períodos sazonais diferentes, principalmente para o $\beta$-cariofileno, que apresentou o maior percentual. A oleorresina de $C$. reticulata Ducke de ambos períodos sazonais foi ativa para as espécies $S$. aureus e $S$. epidermidi, porém, a oleorresina referente ao período seco demonstrou maior atividade, sugerindo que a sazonalidade pode ser um fator determinante diante da atividade antimicrobiana da espécie de copaíba estudada.

\section{REFERÊNCIAS}

ADAMS, P. Identification of Essential Oil Components by Gas Chromatography/Mass Spectrometry. 4 llinois: Allured Publishing Corporation, 2007, 804 p.

BARBOSA, P. C. S. et al. Influence of abiotic factors on the chemical composition of copaiba oil (Copaifera multijuga Hayne): soil composition, seasonality and diameter at breast height. Revista Sociedade Brasileira de Química, v. 23, n. 10, p. 1823 - 1833, 2012.

BAUER, A. W. et al. Antibiotic susceptibility testing by a standardized single disk method. American Journal of Clinical Pathology, v. 45, n. 4, p. 493-496, 1966. 
CARVALHO, L. O.; MIKLE, L. T. Importância terapêutica do óleo-resina de copaíba: enfoque para ação antiinflamatória e cicatrizante. Revista Eletrônica Farmacêutica, v. 11, n. 2, p. 25-36, 2014.

COSTA, B. S. S. Variabilidade espacial de características dendrométricas da copaíba em função da aptidão agrícola em solos do Tocantins. 2017. 124 f. Dissertação (Mestrado em Ciências Florestais e Ambientais) Universidade Federal do Tocantis, Gurupi, 2017.

HECK, M. C.; VIANA, L. A.; VICENTINI, V. E. P. Importância do óleo de Copaifera sp. (copaíba). Revista Saúde e Biologia, v. 7, n. 1, p. 82-90, 2012.

HOLETZ, F. B. et al. Screening of some plants used in the brazilian folk medicine for the treatment of infectious diseases. Memórias do Instituto Oswaldo Cruz, v. 97, n. 7, p. 1027-1031, 2002.

HUANG, M. M. et al. The major volatile organic compound emitted from Arabidopsis thaliana flowers, the sesquiterpene (E)-b-caryophyllene, is a defense against a bacterial pathogen. Journal New Phytologist, v. 193, n. 4, p. 997-1008, 2011.

GARCIA, R. F.; YAMAGUCHI, M. H. Óleo de copaíba e suas propriedades medicinais: revisão bibliográfica. Revista Saúde e Pesquisa, v. 5, n. 1, p. 137146, 2012.

LEANDRO, L. M. et al. Chemistry and Biological Activities of Terpenoids from Copaiba (Copaifera spp.) Oleoresins. Molecules, v.17, n.4, p.3886-3889, 2012.

LIMA, M. C. F. et al. Quantificação do $\beta$-cariofileno e óxido de cariofileno para o controle de qualidade dos óleos de copaíba (Copaifera multijuga Hayne). Brazilian Journal of Development, v. 6, n. 1, p. 608-623, 2020.

LOURENÇO, A. C. S. et al. Óleo de copaíba (Copaifera langsdorfii Desf.) em padrões reprodutivos de camundongos e no desenvolvimento embriofetal. Revista Brasileira de Plantas Medicinais, v. 11, n. 4, p. 407-413, 2009.

LUCCA, L. G. Avaliação da permeação cutânea de nanoemulsão contendo óleo de copaíba incorporada a hidrogéis. 2013. 75 f. Dissertação (Mestrado em Ciências Farmacêuticas) - Universidade Federal do Rio Grande do Sul, Porto Alegre, 2013.

MARTINS-DA-SILVA, R. C. V.; PEREIRA, J. F.; LIMA, H. C. Gênero Copaifera (Leguminosae- Caesalpinioideae) na Amazônia Brasileira. Revista Rodriguésia, v. 59, n. 3, p. 455-476, 2008. 
MARTINELLI, G.; MORAES, M. A. Livro Vermelho da Flora do Brasil Plantas Raras do Cerrado. Rio de Janeiro. Estúdio: Instituto de Pesquisa Jardim Botânico do Rio de Janeiro: CNCFlora, 2014, 320 p.

NASCIMENTO, A. M. A. et al. Synergistic bactericidal activity of Eremanthus erythropappus oil or b-bisabolene with ampicillin against Staphylococcus aureus. Antonie Van Leeuwenhoek, v. 92, n. 1, p. 95-100, 2007.

OLIVEIRA, E. C. P.; LAMEIRA, A. O.; ZOGHBY, M. G. B. Identificação da época de coleta do óleo-resina de copaíba (Copaifera spp.) no município de Moju, PA. Revista Brasileira de Plantas Medicinais, v. 8, n. 3, p. 14-23, 2006.

PACHECO, T. A. R.; BARATA, L. E. S.; DUARTE, M. C. T. Antimicrobial activity of copaíba (Copaifera spp) balsams. Revista Brasileira de Plantas Medicinais, v. 8, n. esp., p. 123-124, 2006.

PEDREIRA, N. E. Avaliação do efeito inibidor tumoral do óleo resina de copaíba in natura (Copaifera reticulata) e manipulado artesanalmente no modelo de carcinogênese bucal experimental DMBA induzida. 2007. $133 \mathrm{f}$. Tese (Doutorado em Patologia Bucal) - Faculdade de Odontologia de Bauru, Unidade Universidade de São Paulo, São Paulo, 2007.

PICHETTE, A. et al. Composition and antibacterial activity of Abies balsamea essential oil. Phytotherapy Research, v. 20, n. 5, p. 371-373, 2006.

PIERI, F. A.; MUSSI, M. C.; MOREIRA, M. A. S. Óleo de copaíba (Copaifera $s p$.$) : histórico, extração, aplicações industriais e propriedades medicinais.$ Revista Brasileira de Plantas Medicinais, v. 11, n. 4, p. 465-472, 2009.

VEIGA JUNIOR, V. F.; PINTO, A. C. O gênero Copaifera L. 2002. Revista Química Nova, v. 25, n. 2, p. 273-286, 2002.

SANTOS, A. O. et al. Antimicrobial activity of Brazilian copaiba oils obtained from different species of the Copaifera genus. Memórias do Instituto Oswaldo Cruz, v. 103, n. 3, p. 277-281, 2008.

ZIECH, R. et al. Atividade antimicrobiana do oleorresina de copaíba (Copaifera reticulata) frente a Staphylococcus coagulase positiva isolados de casos de otite em cães. Pesquisa Veterinária Brasileira, v. 33, n. 7, p. 909-913, 2013.

ZOGHBI, M. G. B. et al. Chemical variation in the volatiles of Copaifera reticulata Ducke (Leguminosae) grouing wild in states of Pará and Amapá, Brazil. Journal of Essential Oil Research, v. 21, n. 6, p. 501-503, 2009. 